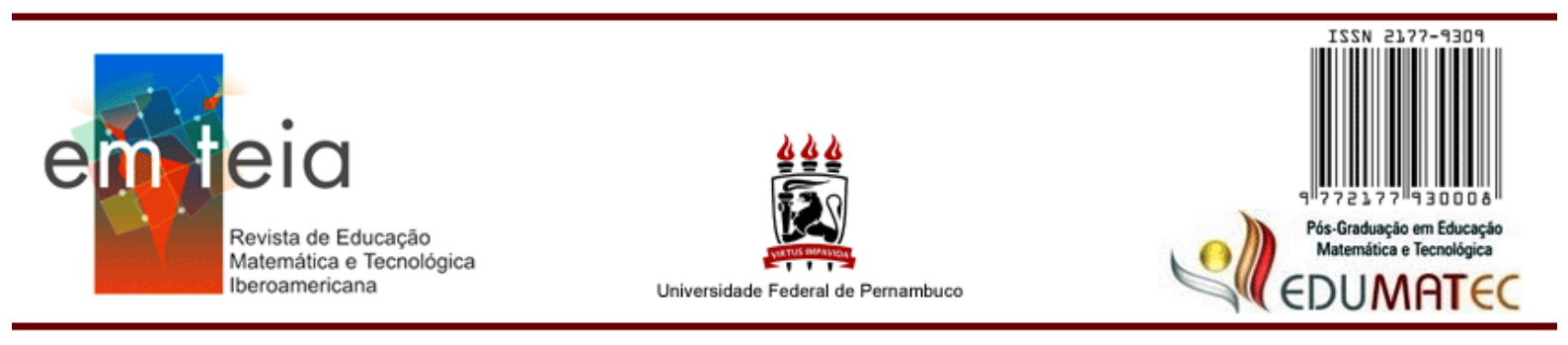

\title{
CENÁRIO DAS PESQUISAS ENVOLVENDO ELABORAÇÃO E RESOLUÇÃO DE PROBLEMAS EM PERIÓDICOS E EVENTOS CIENTÍFICOS
}

\author{
RESEARCH SCENARIO INVOLVING PROBLEM DEVELOPMENT AND \\ RESOLUTION IN JOURNALS AND SCIENTIFIC EVENTS
}

Cidimar Andreatta

cidimar.andreatta@faceli.edu.br Faculdade de Ensino Superior de Linhares - Faceli

Brasil

https://orcid.org/0000-0001-5807-8896

\author{
Norma Suely Gomes Allevato \\ normallev@gmail.com \\ Universidade Cruzeiro do Sul \\ Brasil \\ https://orcid.org/0000-0001-6892-606X
}

\section{Resumo}

O presente artigo, com abordagem qualitativa, apresenta um mapeamento das pesquisas envolvendo Elaboração, Formulação, Proposição e Resolução de Problemas publicadas em periódicos brasileiros e apresentadas em eventos científicos no Brasil e no Exterior, no período de 2011 a 2019. O trabalho teve como fonte de coleta de dados os anais dos eventos/congressos e as edições online dos periódicos com o objetivo de evidenciar focos temáticos dos trabalhos relacionados à Elaboração, Formulação, Proposição e Resolução de Problemas em pesquisas brasileiras e fora do Brasil. Os resultados indicam que quase a totalidade dos trabalhos envolvem a Resolução de Problemas e são frutos de pesquisas vinculadas a cursos de Mestrado na área de Educação Matemática. Tais pesquisas estão relacionadas a contextos de aprendizagem com a utilização de diversos recursos associados à Resolução de Problemas que vão desde a utilização de jogos, calculadora, softwares educativos até materiais concretos como sólidos geométricos.

Palavras-Chave: Elaboração de Problemas, Proposição de Problemas, Formulação de Problemas, Resolução de Problemas, Mapeamento em Educação Matemática.

\begin{abstract}
The present article, of qualitative approach, shows a mapping of research involving Problem Development, Formulation, Proposition and Resolution, published in Brazilian journals and presented in scientific events in Brazil and overseas, from 2011 to 2019. The data were collected from the annals of events/congresses and online editions of journals, aiming to highlight thematic focus of works
\end{abstract}


related to Problem Development, Formulation, Proposition and Resolution in Brazilian and foreign researches. Results show that almost all works involve Problem Resolution and come from researches linked to Master programs in Mathematics Education. Such researches are related to learning contexts by using several resources associated to Problem Resolution, from use of games, calculator, educational software to concrete material, such as geometrical solids.

Keywords: Elaboration of Problems, Proposition of Problems, Formulation of Problems, Problem Solving, Mapping in Mathematics Education.

\section{Introdução}

A Resolução de Problemas - RP, nos últimos anos, vem ganhando destaque nas pesquisas brasileiras e estrangeiras, certamente com perspectivas renovadas, uma vez que é considerada por muitos pesquisadores como o centro da atividade matemática (POLYA, 1978; SCHOENFELD, 2007; VAN de WALLE, 2009). Na matemática escolar ela ganhou força nas pesquisas a partir da década de 1950, com as contribuições teóricas do matemático e pesquisador George Polya, principalmente com um dos seus livros, um clássico na literatura mundial, “A Arte de Resolver Problemas” (POLYA, 1978).

Com o declínio da Matemátia Moderna, o National Council of Teachers of Mathematics - NCTM", em 1980, publicou o documento "Uma agenda para a Ação Recomendações para a Matemática Escolar", propondo que a RP fosse o foco para a Matemática Escolar nos anos 80, e apontando que o problema não poderia ser pensado de forma isolada.

Uma retomada histórica desse surgimento e da consolidação da Resolução de Problemas no cenário internacional e no Brasil foi feita na pesquisa de Morais (2015), destacando que, no Brasil, em 1987, pela primeira vez foi citada, embora de forma incipiente, a Resolução de Problemas como uma preocupação metodológica em um documento de versão preliminar da proposta curricular de Matemática do estado de São Paulo. Morais (2015) aponta, ainda, as contribuições da pesquisa de Fiorentini (1994), segundo a qual os estudos sobre RP se iniciaram em nosso país a partir da segunda metade da década de 80 , ficando muito limitados aos trabalhos de pós-graduação.

Nesse contexto de inserção da RP no campo das pesquisas acadêmicas, ratificamos que o presente artigo apresenta um mapeamento dos trabalhos/pesquisas envolvendo a Elaboração, Formulação, Proposição e Resolução de Problemas publicados em periódicos

\footnotetext{
${ }^{1}$ Conselho Nacional de professores de Matemática dos Estados Unidos.
} 
brasileiros e apresentados em eventos científicos de Educação Matemática, no Brasil e no Exterior, no período de 2011 a 2019.

Por se tratar de periódicos e eventos científicos de relevância para a área de Educação Matemática, com uma concentração significativa de pesquisas, optamos por investigar os trabalhos completos que trouxeram as expressões "Elaboração de Problemas", "Formulação de Problemas", "Proposição de Problemas" e "Resolução de Problemas" em seus títulos. Apresentamos na Tabela 1, a seguir, as edições e periódicos que foram objetos de consulta para o referido mapeamento:

Tabela 1 - Edições dos eventos científicos e periódicos analisados

\begin{tabular}{c|c}
\hline Eventos/Periódicos & Edições/Períodos \\
\hline EBRAPEM & $2011,2012,2013,2014,2015,2016,2017,2018,2019$ \\
\hline SIPEM & $2012,2015,2018$ \\
\hline CIAEM & $2011,2015,2019$ \\
\hline ICME & 2012,2016 \\
\hline Acta Scientiae & 2011 a 2019 \\
\hline Amazônia & 2011 a 2019 \\
\hline Em Teia & 2011 a 2019 \\
\hline $\begin{array}{c}\text { Perspectivas da Educação } \\
\text { Matemática }\end{array}$ & 2011 a 2019 \\
\hline REnCiMa & 2011 a 2019 \\
\hline
\end{tabular}

Assim, este trabalho apresentou, inicialmente, nesta introdução, um breve contexto de surgimento da pesquisa em RP no ensino de Matemática no Brasil e nos Estados Unidos. Na próxima seção apresentamos a caracterização e as peculiaridades dos eventos científicos e periódicos analisados, assim como as origens e autorias dos trabalhos. Na parte metodológica apresentamos a opção pela organização dos trabalhos mapeados em focos temáticos, além de considerações teóricas sobre pesquisas que se constituem como de mapeamentos. Na seção de apresentação e discussão dos dados, exploramos os focos temáticos, que foram selecionados a partir das características dos trabalhos mapeados, suas tendências, convergências e divergências em relação ao foco de investigação deste mapeamento. Finalizamos o texto com as considerações finais e, por fim, listamos as referências.

\section{Caracterização dos eventos científicos analisados}

Encontro Brasileiro de Estudantes de Pós-Graduação em Educação Matemática - Ebrapem

O Ebrapem é um evento de caráter científico que iniciou suas atividades há 22 anos, quando um grupo de estudantes e professores do Programa de Pós-Graduação em Educação 
Matemática da Universidade Estadual Paulista - UNESP/Rio Claro realizou um fórum de debate científico organizado por e para alunos pesquisadores em Educação Matemática, objetivando discussão, troca de experiências e conhecimentos entre os Programas de Educação Matemática. A partir dessa iniciativa surge o I EBRAPEM, realizado em setembro de 1997, na UNESP/Rio Claro (SOCIEDADE BRASILEIRA DE EDUCAÇÃO MATEMÁTICA, 2012).

De 1997 até 2019 o Ebrapem realizou 23 edições. A última em 2019 foi realizada na Universidade Cruzeiro do Sul e contou com a participação de 412 estudantes de mestrado e doutorado que apresentaram trabalhos relacionados às pesquisas que desenvolvem. Esse encontro é organizado em Grupos de Discussão - GDs, coordenados por pesquisadores doutores convidados, onde são apresentados e debatidos os trabalhos na modalidade comunicação oral. Ao longo das edições, os GDs foram se modificando e atualmente a estrutura do Ebrapem integra 17 grupos, sendo a Resolução de Problemas inserida a partir da edição de 2015 no GD de número 14.

Seminário Internacional de Pesquisa em Educação Matemática - Sipem

De acordo com Scarlassari e Lopes (2018), o Sipem é um evento científico da área de Educação Matemática que foi idealizado pela Sociedade Brasileira de Educação Matemática Sbem, com periodicidade de realização a cada três anos, realizado sempre no Brasil, cujo objetivo é promover o intercâmbio entre os pesquisadores que se dedicam aos estudos na área da Educação Matemática "nos diferentes países". Até a última edição, realizada no mês de novembro do ano de 2018, já foram promovidas seis edições, todas no Brasil, sendo a primeira no ano de 2000.

De todas as edições realizadas até o momento, a maior foi a última, em 2018, que contou com 227 trabalhados publicados nos anais, seguida, em quantidade, pela terceira edição, a de 2006, com 211 trabalhos. O Sipem possui 15 grupos de trabalho - GTs envolvendo diversos campos e modalidades de pesquisa desde a Educação Básica até o Ensino Superior, sendo que a Resolução de Problemas não é explicitada em nenhum deles, o que faz com que os trabalhos envolvendo a RP estejam "pulverizados" nos diferentes GTs.

Conferência Interamericana de Educação Matemática - Ciaem

De acordo com o Comitê Interamericano de Educação Matemática, a Ciaem é o primeiro grupo regional criado na Comissão Internacional de Instrução Matemática - ICMI, 
tendo sua primeira edição realizada na Colômbia, em 1961. Diversos países sediaram a conferência desde então, tendo sido realizada a última em 2019, também na Colômbia. A Ciaem vem sendo realizada a cada quatro anos, e até o presente momento já houve quinze edições. Na última edição, em 2019, foram apresentados aproximadamente quatrocentos trabalhos, com a participação de aproximadamente mil profissionais da área de ensino, envolvendo diversos países.

É importante ressaltar que o Brasil e o México concentram o maior número de edições da Ciaem com três edições cada um, assim como percebemos uma maior ocorrência da conferência em países da América do Sul como Colômbia, Argentina, Peru e Uruguai. Essa conferência dispõe de 11 temas de pesquisa para os quais são direcionados os trabalhos dos participantes. Entre eles há aquele para o qual são direcionados os trabalhos envolvendo RP, intitulado Resolução de Problemas e Modelagem Matemática.

Congresso Internacional de Educação Matemática - Icme

O Icme configura-se como um congresso de grande relevância internacional para a Educação Matemática, coordenado pela Comissão Internacional de Instrução Matemática Icmi. É um congresso mundial, o maior da área, de periodicidade quadrienal, que teve sua primeira edição realizada em 1969, e nunca tendo sido realizado no Brasil. As edições do Icme contam com um número elevado de participantes; a última edição, realizada em 2016, em Hamburgo, contou com 745 apresentações entre comunicações orais e posters. A próxima edição do Icme está prevista para ocorrer no ano de 2020, na China.

Em relação à RP, é importande destacar a pesquisa desenvolvida por Morais (2015), que fez uma extensa revisão dos trabalhos envolvendo RP em doze edições do Icme, de 1969 até 2008. O referido trabalho é uma oportunidade de acesso ao cenário das pesquisas internacionais que abordaram o tema nos últimos quarenta anos, tendo em vista que a língua oficial do Icme é o inglês, independente do local em que se realiza.

$\mathrm{Na}$ presente pesquisa, em decorrência disso, buscamos investigar o cenário das pesquisas que envolveram a Elaboração, Formulação, Proposição e Resolução de Problemas nas duas edições posteriores à análise feita por Morais (2015), ou seja, no ICME-12 (2012), realizado na Córeia do Sul e no ICME-13 (2016), realizado na Alemanha. Foram objeto de consulta nas duas edições os trabalhos inseridos no Topic Study Groups - TSG: Problem Solving in Mathematics Education relacionado a RP. 


\section{Caracterização dos periódicos analisados}

Revista de Ensino de Ciências e Matemática - Acta Scientiae

A revista de Ensino de Ciências e Matemática - Acta Scientiae vinculada à Universidade Luterana do Brasil, sob a responsabilidade do Programa de Pós-graduação em Ensino de Ciências e Matemática, teve sua primeira edição publicada em 1999 e, atualmente, possui conceito A1, segundo avaliação 2019 da Capes. Atualmente, o fluxo de submissões na Acta Scientiae é contínuo com publicações de edições a cada dois meses. A partir de 2019 todas as edições são publicadas em inglês com foco em artigos de pesquisas científicas teóricas e empíricas, devidamente embasados nos referenciais teóricos da área de Ensino de Ciências e Matemática consagrados na literatura científica (UNIVERSIDADE LUTERANA DO BRASIL, 2020).

Revista de Educação em Ciências e Matemática - Amazônia

A Revista de Educação em Ciências e Matemática - Amazônia, vinculada ao Programa de Pós-graduação em Educação em Ciências e Matemática do Instituto de Educação Matemática e Científica - IEMCI - da Universidade Federal do Pará, teve sua primeira edição publicada em 2005 e, atualmente, possui conceito A2, segundo avaliação 2019 da Capes. É uma revista com periodicidade de publicação semestral, aberta à comunidade científica, destinada à publicação de pesquisas sobre formação de professores e processos de ensino e de aprendizagem nas áreas de Educação em Ciências (Biologia, Física e Química), Matemática e Educação Ambiental (UNIVERSIDADE FEDERAL DO PARÁ, 2020).

Revista de Educação Matemática e Tecnológica Iberoamericana - Em Teia

A Revista de Educação Matemática e Tecnológica Iberoamericana Em Teia, de periodicidade quadrimestral, está vinculada ao Programa de Pós-graduação em Educação Matemática e Tecnológica - Edumatec da Universidade Federal de Pernambuco e teve sua primeira edição publicada em 2010. Atualmente a revista possui conceito B1 segundo 
avaliação 2019 da Capes e tem por objetivo divulgar pesquisas científicas concluídas na área de Educação Matemática e Tecnológica e áreas afins, com a proposta de criação de redes de contato e de intercâmbios na produção científica e tecnológica (UNIVERSIDADE FEDERAL DE PERNAMBUCO, 2020).

Perspectivas da Educação Matemática

O periódico Perspectivas da Educação Matemática, vinculado ao Programa de Pósgraduação em Educação Matemática da Universidade Federal de Mato Grosso do Sul, possui periodicidade de publicação trimestral. É aberto à comunidade acadêmica, com o objetivo de propiciar espaço de reflexão e debate acerca das questões que envolvem os problemas educacionais contemporâneos, configurados sob a forma de artigos de demanda ou dossiês que veiculem diferentes pontos de vista, convergentes ou divergentes. Na Avaliação da Capes de 2019 obteve conceito de qualificação A3 (UNIVERSIDADE FEDERAL DE MATO GROSSO DO SUL, 2020).

Revista de Ensino de Ciências e Matemática - REnCiMa

A revista REnCiMa é um periódico de publicação trimestral, vinculado ao Programa de Pós-graduação em Ensino de Ciências da Universidade Cruzeiro do Sul. Teve sua primeira edição publicada em 2010 e ao longo de 20 anos já publicou mais de 30 edições envolvendo relatos de pesquisas e trabalhos teóricos que abordam, preferencialmente, resultados de pesquisas e experiências didáticas que tenham como foco a sala de aula e que visem aprimorar os processos de ensino e aprendizagem de conteúdos científicos. Atualmente possui conceito A3, segundo avaliação 2019 da Capes (UNIVERSIDADE CRUZEIRO DO SUL, 2020).

Tendo delineado essas características gerais de cada um dos eventos e periódicos, na Tabela 2, apresentada a seguir, relacionamos a quantidade de trabalhos mapeados neste artigo. Percebemos que o Ebrapem concentra o maior número de trabalhos, tendo em vista que sua realização é anual e concentrou 9 edições analisadas.

Tabela 2 - Quantidade de trabalhos mapeados por eventos científicos e periódicos

\begin{tabular}{c|c|c}
\hline Eventos/Periódicos & Quantidade de edições & $\begin{array}{c}\text { Quantidade de } \\
\text { trabalhos mapeados }\end{array}$ \\
\hline EBRAPEM & 09 & 125 \\
\hline SIPEM & 03 & 16 \\
\hline CIAEM & 03 & 56 \\
\hline ICME & 02 & 23 \\
\hline Acta Scientiae & 39 & 08 \\
\hline Amazônia & 20 & 05 \\
\hline
\end{tabular}




\begin{tabular}{c|c|c}
\hline Em Teia & 26 & 07 \\
\hline $\begin{array}{c}\text { Perspectivas da Educação } \\
\text { Matemática }\end{array}$ & 16 & 05 \\
\hline REnCiMa & 33 & 09 \\
\hline Total & 151 & 254 \\
\hline \multicolumn{2}{c}{ Fonte: Dados de pesquisa }
\end{tabular}

\section{As origens e autorias dos trabalhos ${ }^{2}$}

Por se tratar de um trabalho envolvendo mapeamento de pesquisas publicadas em periódicos e apresentadas em diferentes eventos científicos realizados no Brasil e no Exterior, há uma diversidade grande de autores e instituções responsáveis pelos trabalhos, assim como de países de que esses pesquisadores são oriundos. No contexto internacional, percebemos que o maior número de pesquisas está concentrado nos Estados Unidos, Colômbia, Portugal e México, disponibilizadas predominantemente nos anais dos eventos Ciaem e Icme. No contexto nacional, o maior número de pesquisas está concentrado na região Sudeste do Brasil.

A maior parte dos trabalhos está vinculada ao estado de São Paulo, na região Sudeste, e no Rio Grande do Sul, na região Sul. Uma grande parte dos trabalhos é oriunda de pesquisas stricto sensu, vinculadas a programas de mestrado em Educação Matemática. É curioso destacar que dos 125 trabalhos mapeados dos Ebrapems realizados nesses nove anos, somente 20 são de pesquisas do doutorado.

No grupo de trabalhos estrangeiros, é importante destacar que a maior parte é fruto do Icme e da Ciaem, principalmente por serem eventos sediados por instituições de fora do Brasil. Percebemos que tais trabalhos envolvem, também, pesquisas de professores e pesquisadores, ou seja, os autores, em geral, não são acadêmicos de cursos de mestrado e doutorado. No contexto da Ciaem, dos 56 trabalhos mapeados, 37 são oriundos de pesquisas desenvolvidas no Brasil, principalmente na região Sudeste. Em relação ao Icme, não identificamos trabalhos brasileiros nas edições mapeadas.

Em se tratando das instituições de ensino a que se vinculam os autores dos trabalhos brasileiros, é importante destacar que a Universidade Estadual da Paraíba - UEPB concentrou o maior número de pesquisas, seguida da Universidade Estadual Paulista - Unesp, Universidade do Vale do Taquari - Univates, Universidade Federal de Pernambuco - UFPE, Universidade Luterana do Brasil - Ulbra, Universidade Cruzeiro do Sul - Unicsul, entre outras.

\footnotetext{
2 Tendo em vista a quantidade de trabalhos analisados neste mapeamento, optamos por apresentar as referências, ao final do artigo, somente dos trabalhos citados diretamente no texto.
} 


\section{Metodologia da pesquisa}

O presente trabalho é de natureza metodológica exploratória e bibliográfica, de abordagem qualitativa do tipo estado do conhecimento, uma vez que se refere a um campo específico de investigação acerca de uma temática restrita, nesse caso a Resolução de Problemas (ROMANOWSKI; ENS, 2006). O objetivo é apresentarmos análises das pesquisas apresentadas nos eventos e publicadas nos periódicos citados na Tabela 1, nas modalidades de relatos de experiências e comunicações científicas.

É exploratória e bibliográfica devido ao processo de definição e constituição dos dados e às fontes de informações coletadas na leitura dos títulos e resumos dos trabalhos organizados no mapeamento. É bibliográfica, também, pois foi constituida com quadros de referências teóricas, sem a utilização de pesquisa empírica, indo ao encontro das considerações de Fiorentini e Lorenzato (2012).

Fiorentini (2002) destaca que são diversas as formas de organização ou categorização de trabalhos: pela metodologia da pesquisa utilizada, pelo referencial teórico, pelos objetivos de investigação ou pelos paradigmas epistemológicos da pesquisa, entre outras possibilidades. No presente trabalho, a opção foi por focos temáticos, indo ao encontro das indicações registradas no trabalho de mapeamento realizado por Fiorentini (2002, p. 4), que destaca:

[...] essa forma de organização exige que se identifique, para cada trabalho, o foco principal da investigação. Esse processo não é simples ou direto, pois acontece de forma indutiva e, às vezes, dedutiva, exigindo ajustes individuais (para cada estudo) e grupais (envolvendo um conjunto de estudos). A vantagem é que as categorias construídas emergem do material sob análise e não da literatura propriamente dita, embora, neste processo, o diálogo com a literatura e outras formas de classificação seja conveniente e necessário.

Percebemos, na citação, a importância e vantagem de realizar trabalhos de mapeamento, pois as características e os focos de investigação dos trabalhos emergem das análises minuciosas dos mesmos e não da literatura propriamente dita. No presente estudo, as análises obtidas principalmente através dos resumos dos trabalhos foram organizadas em focos e subfocos temáticos, de acordo com essas orientações metodológicas. Em muitos casos foi necessário realizar a leitura integral dos trabalhos organizados neste mapeamento.

Nas próximas seções, apresentamos os focos temáticos que identificamos nos trabalhos, assim como as considerações e análises relacionadas às convergências e divergências em relação à RP.

\section{Focos temáticos, tendências e convergências dos trabalhos}


Conforme já explicitado, optamos por organizar os trabalhos mapeados nesta pesquisa em focos temáticos de acordo com as considerações de Fiorentini (2002). Organizar trabalhos tematicamente não é tarefa fácil, mas permite-nos identificar e comparar os diferentes olhares e resultados produzidos pelas pesquisas, independentemente das opções teóricas e metodológicas dos autores. Os trabalhos que analisamos foram, então, organizados em sete focos temáticos, conforme evidenciado na Tabela 3, apresentada a seguir:

Tabela 3 - Distribuição dos trabalhos nos focos temáticos

\begin{tabular}{|c|c|c|}
\hline FOCOS TEMÁTICOS & $\begin{array}{l}\text { QUANTIDADE } \\
\text { DE }\end{array}$ & PERCENTUAL \\
\hline $\begin{array}{l}\text { Estudos com a RP nos Anos Iniciais do Ensino } \\
\text { Fundamental }\end{array}$ & 37 & 14,6 \\
\hline $\begin{array}{l}\text { Estudos com a RP nos Anos Finais do Ensino } \\
\text { Fundamental }\end{array}$ & 48 & 18,9 \\
\hline Estudos com a RP no Ensino Médio & 46 & 18,1 \\
\hline Estudos com a RP no Ensino Superior & 15 & 5,9 \\
\hline Estudos com a RP no campo teórico-bibliográfico & 25 & 9,8 \\
\hline $\begin{array}{l}\text { Estudos com a RP sobre o professor de Matemática: } \\
\text { formação inicial e continuada }\end{array}$ & 79 & 31,1 \\
\hline Estudos com a RP no campo da Educação Não Formal & 04 & 1,6 \\
\hline Total & 254 & 100,0 \\
\hline
\end{tabular}

Fonte: Dados de pesquisa

A Tabela 3 nos permite inferir que o foco temático "Estudos com a RP sobre o professor de Matemática: formação inicial e continuada" possui a maior quantidade de trabalhos, seguido dos focos "Estudos com a RP nos Anos Finais do Ensino Fundamental" e "Estudos com a RP no Ensino Médio" De um modo geral, percebemos que os estudos, na maior parte, estão concentrados na Educação Básica e relacionados à utilização da RP com diferentes recursos e materiais, assim como em diversos ambientes de aprendizagem, como softwares educativos.

O foco temático "Estudos com a RP no Ensino Superior" está direcionado a pesquisas vinculadas a cursos de bacharelados e tecnológicos e que não envolvem formação inicial e/ou continuada de professores. A maior parte dos trabalhos organizados neste foco é oriunda de cursos nas áreas de engenharia e empresariais.

Em todo o corpus analisado, identificamos além desses sete focos temáticos, 14 subfocos que estão organizados nas tabelas 4, 5, 6, 7, 8, 9 e 10. Optamos por apresentar a organização dos 254 trabalhos em tabelas específicas para cada foco temático, tendo em vista a grande quantidade de trabalhos incluídos neste mapeamento. Então propusemos uma discussão contextualizada em cada foco organizado neste estudo. Ressaltamos que há 
subfocos temáticos que se repetem nos focos, por exemplo o subfoco "Estratégias/habilidades na RP com diferentes recursos e ambientes de aprendizagem", demonstrando convergências em relação aos objetivos de alguns estudos, mesmo quando se referem a focos diferentes.

Na Tabela 4 apresentamos a organização dos trabalhos no primeiro foco temático das pesquisas que envolvem práticas pedagógicas com estudantes dos anos iniciais do ensino fundamental.

Tabela 4 - Distribuição dos trabalhos no primeiro foco temático

\begin{tabular}{|c|c|c|c|c|}
\hline Foco Temático & $\begin{array}{c}\mathbf{N}^{\circ} \text { de } \\
\text { Trabalhos }\end{array}$ & Subfoco & Autores & $\begin{array}{l}\text { Eventos/ } \\
\text { Periódicos }\end{array}$ \\
\hline \multirow{10}{*}{$\begin{array}{l}\text { Estudos com a } \\
\text { RP nos Anos } \\
\text { Iniciais do } \\
\text { Ensino } \\
\text { Fundamental }\end{array}$} & \multirow{10}{*}{10} & \multirow{10}{*}{$\begin{array}{l}\text { A RP como estratégia de } \\
\text { ensino para o } \\
\text { desenvolvimento de } \\
\text { conteúdos/conceitos } \\
\text { matemáticos }\end{array}$} & Silva/Spinillo (2011) & CIAEM \\
\hline & & & Fiore/Galvão (2012) & EBRAPEM \\
\hline & & & Zaran/Santos (2012) & EBRAPEM \\
\hline & & & Altoé (2016) & EBRAPEM \\
\hline & & & Spinillo/Silva (2016) & Em Teia \\
\hline & & & Melo et al. (2016) & Em Teia \\
\hline & & & Oliveira Junior (2018) & SIPEM \\
\hline & & & Lautert et al. (2018) & SIPEM \\
\hline & & & Carvalho (2018) & EBRAPEM \\
\hline & & & Justo (2019) & Em Teia \\
\hline
\end{tabular}

\begin{tabular}{|c|c|c|c|c|}
\hline Foco Temático & $\begin{array}{c}\mathrm{N}^{o} \mathrm{de} \\
\text { Trabalhos }\end{array}$ & Subfoco & Autores & $\begin{array}{c}\text { Eventos/ } \\
\text { Periódicos }\end{array}$ \\
\hline \multirow{27}{*}{$\begin{array}{l}\text { Estudos com a } \\
\text { RP nos Anos } \\
\text { Iniciais do } \\
\text { Ensino } \\
\text { Fundamental }\end{array}$} & \multirow{10}{*}{10} & \multirow{10}{*}{$\begin{array}{l}\text { Leitura, interpretação e } \\
\text { concepção de problemas } \\
\text { matemáticos }\end{array}$} & Lautert/Ferreira (2011) & CIAEM \\
\hline & & & Coutinho (2011) & CIAEM \\
\hline & & & Pontes/Borba (2012) & EBRAPEM \\
\hline & & & Cybis (2013) & EBRAPEM \\
\hline & & & Sena (2014) & EBRAPEM \\
\hline & & & Klieman/Dullius (2017) & Amazônia \\
\hline & & & Soto/Riquelme (2019) & CIAEM \\
\hline & & & Montes (2019) & CIAEM \\
\hline & & & Diaz et al. (2019) & CIAEM \\
\hline & & & Leonardo (2019) & EBRAPEM \\
\hline & \multirow{10}{*}{10} & \multirow{10}{*}{$\begin{array}{l}\text { Estratégias/habilidades na } \\
\mathrm{RP} \text { com diferentes } \\
\text { recursos e ambientes de } \\
\text { aprendizagem }\end{array}$} & Henriquez et al. (2011) & CIAEM \\
\hline & & & Faustino (2012) & EBRAPEM \\
\hline & & & Rott (2012) & ICME \\
\hline & & & Magina et al. (2015) & SIPEM \\
\hline & & & Justo et al. (2015) & CIAEM \\
\hline & & & Rasch/Schnotz (2016) & ICME \\
\hline & & & Gadelha (2018) & EBRAPEM \\
\hline & & & Aguilera (2019) & CIAEM \\
\hline & & & Kaminski/Bosc (2019) & CIAEM \\
\hline & & & Silva (2019) & EBRAPEM \\
\hline & \multirow{4}{*}{04} & \multirow{4}{*}{$\begin{array}{l}\text { A Formulação e Resolução } \\
\text { de Problemas em contextos } \\
\text { de } \\
\text { matemática }\end{array}$} & Santos/Camargo (2011) & CIAEM \\
\hline & & & Silva (2014b) & EBRAPEM \\
\hline & & & Fonteque (2016) & EBRAPEM \\
\hline & & & Altoé/Freitas (2019) & Em Teia \\
\hline & \multirow{3}{*}{03} & \multirow{3}{*}{$\begin{array}{l}\text { A metodologia de Ensino- } \\
\text { Aprendizagem-Avaliação } \\
\text { de Matemática através da }\end{array}$} & Vallilo (2016) & EBRAPEM \\
\hline & & & Andreatta (2018) & EBRAPEM \\
\hline & & & Poffo (2019) & EBRAPEM \\
\hline
\end{tabular}


Os subfocos expressam aspectos específicos percebidos nesses estudos, ou seja, as práticas pedagógicas envolvendo a Formulação, Elaboração, Proposição e Resolução de Problemas nos anos iniciais do ensino fundamental. Estão relacionadas à RP como estratégia de ensino para a aprendizagem de conteúdos e conceitos matemáticos; à utlização da RP com diferentes recursos e ambientes de aprendizagem; as investigações das produções escritas pelos estudantes, da leitura e interpretação do enunciado dos problemas; da Formulação de Problemas em contextos de aprendizagem matemática, assim como da metodologia de Ensino-Aprendizagem-Avaliação de Matemática através da RP, totalizando 37 trabalhos nesse primeiro foco temático.

Ressaltamos a existência da pesquisa de Altoé e Freitas (2019) relacionada especificamente à Formulação de Problemas, que buscou oportunizar aos estudantes do $5^{\circ}$ ano do Ensino Fundamental uma experiência envolvendo problemas combinatórios. Presenciamos também 3 trabalhos que estão direcionados à metodologia de Ensino-AprendizagemAvaliação de Matemática através da RP apresentados recentemente no Ebrapem, além de outros subfocos envolvendo a RP em contextos de aprendizagem.

É importante considerar, ainda, que este primeiro foco temático concentra a maior parte dos trabalhos relacionados à RP apresentados na edição da XV CIAEM, realizada na Colômbia, no ano de 2019, e envolveu pesquisas que investigaram os registros e a produção de problemas por estudantes dos primeiros anos de escolarização. Essas pesquisas são oriundas, principalmente, do México e do Chile.

Os trabalhos envolvendo o segundo foco temático, relacionado aos estudos com a RP nos Anos Finais do Ensino Fundamental, foram organizados na Tabela 5 e somam 48 trabalhos.

Tabela 5 - Distribuição dos trabalhos no segundo foco temático

\begin{tabular}{|c|c|c|c|c|}
\hline $\begin{array}{c}\text { Foco } \\
\text { Temático }\end{array}$ & $\begin{array}{c}\mathrm{N}^{0} \text { de } \\
\text { trabalhos }\end{array}$ & Subfoco & Autores & $\begin{array}{l}\text { Eventos/ } \\
\text { Periódicos }\end{array}$ \\
\hline \multirow{10}{*}{$\begin{array}{l}\text { Estudos com } \\
\text { a RP nos } \\
\text { Anos Finais } \\
\text { do Ensino } \\
\text { Fundamen- } \\
\text { tal }\end{array}$} & \multirow{10}{*}{11} & \multirow{10}{*}{$\begin{array}{l}\text { A RP como estratégia de } \\
\text { ensino para o } \\
\text { desenvolvimento de } \\
\text { conteúdos/conceitos } \\
\text { matemáticos }\end{array}$} & Justo/Echeveste (2011) & CIAEM \\
\hline & & & Goulart (2012) & EBRAPEM \\
\hline & & & Vargas/Bisognin (2012) & EBRAPEM \\
\hline & & & Silva/Savioli (2012) & EBRAPEM \\
\hline & & & Jiang/Fu (2012) & $\mathrm{ICME}$ \\
\hline & & & Asami-Johansson (2012) & ICME \\
\hline & & & Yazgan/Arslan (2012) & ICME \\
\hline & & & Pita (2014) & EBRAPEM \\
\hline & & & Moretti/Brandt (2014) & Acta Scientiae \\
\hline & & & Ferreira $(2015)$ & EBRAPEM \\
\hline
\end{tabular}




\begin{tabular}{|c|c|c|c|c|}
\hline & & & Groenwald (2018) & SIPEM \\
\hline & \multirow{6}{*}{06} & \multirow{6}{*}{$\begin{array}{l}\text { A RP como estratégia de } \\
\text { ensino para o } \\
\text { desenvolvimento de } \\
\text { conteúdos/conceitos } \\
\text { matemáticos }\end{array}$} & Martinez et al. (2019) & CIAEM \\
\hline & & & Stein (2019) & EBRAPEM \\
\hline & & & Sá (2019) & EBRAPEM \\
\hline & & & Kucinskas (2019) & EBRAPEM \\
\hline & & & Meinerz (2019) & EBRAPEM \\
\hline & & & Delazari/Groenwald (2019) & $\begin{array}{l}\text { Perspectivas da } \\
\text { Educação Mat. }\end{array}$ \\
\hline & \multirow{10}{*}{10} & \multirow{10}{*}{$\begin{array}{l}\text { Estratégias/habilidades na } \\
\mathrm{RP} \text { com diferentes } \\
\text { recursos e ambientes de } \\
\text { aprendizagem }\end{array}$} & Coelho et al. (2011) & CIAEM \\
\hline & & & Grando/Hubner (2011) & CIAEM \\
\hline & & & Santos/Santos (2011) & EBRAPEM \\
\hline & & & Jacinto/Carreira (2012) & ICME \\
\hline & & & Yang/Wilensky (2012) & ICME \\
\hline & & & Manouchehri et al. (2012) & ICME \\
\hline & & & Furlanetto/Dullius (2012) & EBRAPEM \\
\hline & & & Lopes/Magina (2012) & SIPEM \\
\hline & & & Lima (2013) & EBRAPEM \\
\hline & & & Althaus (2013) & EBRAPEM \\
\hline $\begin{array}{c}\text { Foco } \\
\text { Temático } \\
\end{array}$ & $\begin{array}{c}\mathrm{N}^{0} \mathrm{de} \\
\text { trabalhos }\end{array}$ & Subfoco & Autores & $\begin{array}{c}\text { Eventos/ } \\
\text { Periódicos }\end{array}$ \\
\hline \multirow{22}{*}{$\begin{array}{l}\text { Estudos com } \\
\text { a RP nos } \\
\text { Anos Finais } \\
\text { do Ensino } \\
\text { Fundamen- } \\
\text { tal }\end{array}$} & \multirow{6}{*}{06} & \multirow{6}{*}{$\begin{array}{l}\text { Estratégias/habilidades na } \\
\mathrm{RP} \text { com diferentes } \\
\text { recursos e ambientes de } \\
\text { aprendizagem }\end{array}$} & Araujo (2014) & EBRAPEM \\
\hline & & & Dullius et al. (2015) & SIPEM \\
\hline & & & Jacinto/Carreira (2016) & ICME \\
\hline & & & Pranke (2017) & EBRAPEM \\
\hline & & & Muller/Dullius (2018) & SIPEM \\
\hline & & & Teixeira et al. (2019) & CIAEM \\
\hline & \multirow{7}{*}{07} & \multirow{7}{*}{$\begin{array}{l}\text { Leitura, interpretação e } \\
\text { concepção de problemas } \\
\text { matemáticos }\end{array}$} & Silva/Carvalho (2011) & EBRAPEM \\
\hline & & & Gonçalves/Freitas (2012) & Em Teia \\
\hline & & & Muller $(2013)$ & EBRAPEM \\
\hline & & & Leite (2014) & EBRAPEM \\
\hline & & & Vega (2014) & EBRAPEM \\
\hline & & & Alvarenga et al. (2016) & Amazônia \\
\hline & & & Lima et al. (2018) & Amazônia \\
\hline & \multirow{3}{*}{03} & \multirow{3}{*}{$\begin{array}{ll}\text { A Formulação e Resolução } \\
\text { de Problemas em contextos } \\
\text { de } & \text { aprendizagem } \\
\text { matemática } & \end{array}$} & Almeida/Fiorentini (2011) & CIAEM \\
\hline & & & Coelho/Marco (2019) & REnCiMa \\
\hline & & & Figueiredo et al. (2019) & Em Teia \\
\hline & \multirow{4}{*}{04} & \multirow{4}{*}{$\begin{array}{l}\text { A metodologia Ensino- } \\
\text { Aprendizagem-Avaliação } \\
\text { de Matemática através da } \\
\text { RP }\end{array}$} & Morais/Onuchic (2011) & CIAEM \\
\hline & & & Silva (2016) & EBRAPEM \\
\hline & & & Pironel (2019) & EBRAPEM \\
\hline & & & Melo (2019) & EBRAPEM \\
\hline & \multirow{2}{*}{01} & \multirow{2}{*}{$\begin{array}{l}\text { A RP como recurso para a } \\
\text { aprendizagem de questões } \\
\text { ambientais }\end{array}$} & Ribeiro et al. (2019) & Acta Scientiae \\
\hline & & & & \\
\hline
\end{tabular}

Fonte: Dados de pesquisa

Neste foco temático presenciamos um subfoco a mais em relação ao primeiro foco temático, que está relacionado a um trabalho que envolveu a RP como suporte para a aprendizagem de questões ambientais. Percebemos uma grande congruência de trabalhos que investigam a aprendizagem discente utilizando RP com diferentes recursos e ambientes de aprendizagem, assim como a utilização da RP como estratégia de ensino para a aprendizagem 
de conteúdos e conceitos matemáticos. A professora e pesquisadora Maria Madalena Dullius, da Universidade do Vale do Taquari - Univates, possui três trabalhos inseridos neste foco temático (FURLANETTO; DULLIUS, 2012; DULLIUS et al. 2015; MULLER; DULLIUS, 2018). Tais trabalhos são, geralmente, frutos de orientação acadêmica, assim como de pesquisas que utilizam diversificadas estratégias de RP a fim de melhorar a qualidade do ensino e a aprendizagem matemática. O primeiro trabalho foi apresentado no Ebrapem e os outros dois no Sipem.

É importante considerar também que tivemos neste foco temático a concentração de 6 trabalhos apresentados na última edição do Ebrapem, realizada em outubro de 2019. A maior parte desses trabalhos está direcionada para pesquisas com o objetivo de utilizar a RP como estratégia de ensino, considerando a aprendizagem de equações do $1^{\mathrm{o}}$ grau, frações, sólidos geométricos, entre outros.

Foi neste segundo foco temático, envolvendo a RP nos Anos Finais do Ensino Fundamental, que tivemos o maior número de trabalhos mapeados oriundos do ICME, concentrando 07 trabalhos, sendo a maioria deles também agrupados no subfoco temático relacionado à RP com diferentes recursos e ambientes de aprendizagem.

No terceiro foco temático organizamos trabalhos que se referem a práticas com estudantes do Ensino Médio. Eles estão mapeados em seis subfocos temáticos apresentados na Tabela 6 e somam 46 trabalhos, sendo a maioria oriundos dos eventos Ciaem e Ebrapem. Neste foco foram constituídos dois subfocos que ainda não tinham sido considerados. Um deles está relacionado à RP associada às representações semióticas e o outro à RP envolvendo questões curriculares e estudos de livros didáticos.

Tabela 6 - Distribuição dos trabalhos no terceiro foco temático

\begin{tabular}{|c|c|c|c|c|}
\hline $\begin{array}{c}\text { Foco } \\
\text { Temático }\end{array}$ & $\begin{array}{c}\mathrm{N}^{0} \text { de } \\
\text { trabalhos }\end{array}$ & Subfoco & Autores & $\begin{array}{l}\text { Eventos/ } \\
\text { Periódicos }\end{array}$ \\
\hline \multirow{15}{*}{$\begin{array}{c}\text { Estudos com } \\
\text { a RP no } \\
\text { Ensino } \\
\text { Médio }\end{array}$} & \multirow{10}{*}{10} & \multirow{10}{*}{$\begin{array}{l}\text { A RP como estratégia de } \\
\text { ensino para } \\
\text { desenvolvimento } \\
\text { conteúdos/conceitos } \\
\text { matemáticos }\end{array}$} & Martins/Andrade (2011) & EBRAPEM \\
\hline & & & Nascimento/Andrade (2011) & EBRAPEM \\
\hline & & & Lima/Miranda (2012) & EBRAPEM \\
\hline & & & Brandão/Andrade (2012) & EBRAPEM \\
\hline & & & Silva/Andrade (2012) & EBRAPEM \\
\hline & & & Ban et al. (2012) & ICME \\
\hline & & & Soifer (2012) & ICME \\
\hline & & & Meira (2013) & EBRAPEM \\
\hline & & & Brandão (2014) & EBRAPEM \\
\hline & & & $\operatorname{Lima}(2014 a)$ & EBRAPEM \\
\hline & \multirow{4}{*}{04} & \multirow{4}{*}{$\begin{array}{ll}\text { A RP como estratégia de } & \text { de } \\
\text { ensino para } & \text { o } \\
\text { desenvolvimento } & \text { de } \\
\text { conteúdos/conceitos } & \\
\text { matemáticos } & \\
\end{array}$} & Gonçalves (2014) & EBRAPEM \\
\hline & & & Rodrigues et al. (2015) & CIAEM \\
\hline & & & Viana (2015) & SIPEM \\
\hline & & & Amado et al. (2016) & ICME \\
\hline & & & Paiva et al. (2011) & CIAEM \\
\hline
\end{tabular}




\begin{tabular}{|c|c|c|c|c|}
\hline & \multirow{12}{*}{13} & \multirow{12}{*}{$\begin{array}{l}\text { Estratégias/habilidades na } \\
\text { RP com diferentes recursos } \\
\text { e ambientes de } \\
\text { aprendizagem }\end{array}$} & Pacheco/Roazzi (2011) & CIAEM \\
\hline & & & Lopes/Magina (2011) & EBRAPEM \\
\hline & & & Souza/Bianchini (2012) & EBRAPEM \\
\hline & & & Ashna/Sam (2012) & ICME \\
\hline & & & Lopes (2012) & SIPEM \\
\hline & & & Segantini (2014) & EBRAPEM \\
\hline & & & Santana (2014) & EBRAPEM \\
\hline & & & Souza/Silva (2015) & CIAEM \\
\hline & & & Meira/Medeiros (2015) & CIAEM \\
\hline & & & Braga/Sa (2015) & CIAEM \\
\hline & & & Zamorano/Arias (2015) & CIAEM \\
\hline & & & Viegas (2016) & EBRAPEM \\
\hline $\begin{array}{c}\text { Foco } \\
\text { Temático } \\
\end{array}$ & $\begin{array}{c}\mathrm{N}^{0} \mathrm{de} \\
\text { trabalhos }\end{array}$ & Subfoco & Autores & $\begin{array}{c}\text { Eventos/ } \\
\text { Periódicos }\end{array}$ \\
\hline \multirow{20}{*}{$\begin{array}{l}\text { Estudos com } \\
\text { a RP no } \\
\text { Ensino } \\
\text { Médio }\end{array}$} & \multirow{6}{*}{06} & \multirow{6}{*}{$\begin{array}{l}\text { Leitura, interpretação e } \\
\text { concepção de problemas } \\
\text { matemáticos }\end{array}$} & Ribeiro/kaiber (2012) & EBRAPEM \\
\hline & & & Martins (2014) & EBRAPEM \\
\hline & & & Braga (2014) & EBRAPEM \\
\hline & & & Meira (2014) & EBRAPEM \\
\hline & & & Kuntz (2018) & EBRAPEM \\
\hline & & & Hernandez (2019) & CIAEM \\
\hline & \multirow{7}{*}{07} & \multirow{7}{*}{$\begin{array}{l}\text { A metodologia de Ensino- } \\
\text { Aprendizagem-Avaliação } \\
\text { de Matemática através da } \\
\text { RP }\end{array}$} & Pagani (2015) & $\overline{\text { EBRAPEM }}$ \\
\hline & & & Pagani/Allevato (2016) & REnCiMa \\
\hline & & & Pagani (2019) & CIAEM \\
\hline & & & Fernandes (2019) & EBRAPEM \\
\hline & & & Severo (2019) & EBRAPEM \\
\hline & & & Gonçalves (2019) & EBRAPEM \\
\hline & & & Vargas (2019) & EBRAPEM \\
\hline & \multirow{3}{*}{03} & \multirow{3}{*}{$\begin{array}{l}\text { A Formulação e Resolução } \\
\text { de Problemas em contextos } \\
\text { de } \\
\text { matemática }\end{array}$} & Souza (2013) & EBRAPEM \\
\hline & & & Silva (2013a) & EBRAPEM \\
\hline & & & Souza (2014) & EBRAPEM \\
\hline & \multirow{3}{*}{02} & \multirow{3}{*}{$\begin{array}{l}\text { A RP como estratégia para } \\
\text { o ensino de teorias, } \\
\text { questões curriculares e } \\
\text { livros didáticos }\end{array}$} & Dessoy (2013) & EBRAPEM \\
\hline & & & Dessoy (2014) & EBRAPEM \\
\hline & & & & \\
\hline & 01 & $\begin{array}{l}\text { A RP no contexto da } \\
\text { Representação Semiótica }\end{array}$ & Rodrigues/Carrião (2011) & CIAEM \\
\hline
\end{tabular}

Fonte: Dados de pesquisa

Corroborando as discussões relacionadas ao terceiro foco temático, percebemos que há um balanceamento em relação à quantidade de trabalhos categorizados nos subfocos envolvendo as estratégias/habilidades na RP com diferentes recursos e ambientes de aprendizagem, assim como na RP como estratégia de ensino para o desenvolvimento de conteúdos/conceitos matemáticos. Alguns propõem a utilização da RP com recursos como jogos, calculadora, sólidos geométricos, softwares educativos, bem como a RP com foco para aprendizagem de conteúdos de geometria espacial, equações do $1^{\circ}$ grau, funções quadráticas, análise combinatória, entre outros. 
É importante considerar a identificação de três trabalhos de mesma autoria (PAGANI, 2015, 2019; PAGANI; ALLEVATO, 2016), agrupados no subfoco "A metodologia de Ensino-Aprendizagem-Avaliação de Matemática através da Resolução de Problemas", vinculados à pesquisa de doutorado que investigou o processo de ensino e aprendizagem de derivadas com estudantes do ensino médio no contexto da RP. Todos os trabalhos vinculados neste subfoco citam as contribuições teóricas das autoras Allevato e Onuchic (2014) como referencial metodológico para aplicação dos problemas, propostos com foco na produção de conceitos matemáticos.

No quarto foco temático houve uma concentração menor de trabalhos; ele envolve pesquisas que investigam práticas docentes no Ensino Superior e que não estão relacionadas à formação de professores. São trabalhos, muitas vezes, direcionados a cursos nas áreas de engenharias e empresariais, sendo a maior concentração envolvendo pesquisas que utilizam a RP como estratégia de ensino para a aprendizagem de conteúdos e conceitos matemáticos. $\mathrm{Na}$ Tabela 7 apresentamos a categorização desses trabalhos.

Tabela 7 - Distribuição dos trabalhos no quarto foco temático

\begin{tabular}{|c|c|c|c|c|}
\hline $\begin{array}{c}\text { Foco } \\
\text { Temático }\end{array}$ & $\begin{array}{c}\mathrm{N}^{0} \text { de } \\
\text { trabalhos }\end{array}$ & Subfoco & Autores & $\begin{array}{c}\text { Eventos/ } \\
\text { Periódicos }\end{array}$ \\
\hline \multirow{16}{*}{$\begin{array}{l}\text { Estudos } \\
\text { com a RP } \\
\text { no Ensino } \\
\text { Superior }\end{array}$} & \multirow{4}{*}{04} & \multirow{4}{*}{$\begin{array}{l}\text { Estratégias/habilidades na } \\
\text { RP com diferentes recursos } \\
\text { e ambientes de } \\
\text { aprendizagem }\end{array}$} & Toso et al. (2011) & CIAEM \\
\hline & & & Matassa et al. (2011) & CIAEM \\
\hline & & & Epperson et al. (2016) & ICME \\
\hline & & & Duarte (2017) & EBRAPEM \\
\hline & \multirow{4}{*}{04} & \multirow{4}{*}{$\begin{array}{l}\text { A metodologia de Ensino- } \\
\text { Aprendizagem-Avaliação } \\
\text { de Matemática através da } \\
\text { RP }\end{array}$} & Sosa/Olimpio Junior (2012) & Acta Scientiae \\
\hline & & & Leal Junior/Onuchic (2018) & $\begin{array}{l}\text { Perspectivas da } \\
\text { Ed. Matemática }\end{array}$ \\
\hline & & & Bertotti Junior (2019) & EBRAPEM \\
\hline & & & Homa (2019) & EBRAPEM \\
\hline & \multirow{3}{*}{03} & \multirow{3}{*}{$\begin{array}{l}\text { Leitura, interpretação e } \\
\text { concepção de problemas } \\
\text { matemáticos }\end{array}$} & $\operatorname{Ng}(2012)$ & $\mathrm{ICME}$ \\
\hline & & & Enriquez/Efremov (2015) & CIAEM \\
\hline & & & Gallardo et al. (2019) & CIAEM \\
\hline & \multirow{3}{*}{03} & \multirow{3}{*}{$\begin{array}{l}\text { A RP como estratégia de ensino } \\
\text { para o desenvolvimento de } \\
\text { conteúdos/conceitos } \\
\text { matemáticos }\end{array}$} & Gaffuri/Bisognin (2012) & EBRAPEM \\
\hline & & & Diaz/Machin (2012) & ICME \\
\hline & & & Azevedo (2016) & EBRAPEM \\
\hline & \multirow{2}{*}{01} & \multirow{2}{*}{$\begin{array}{l}\text { A Formulação e Resolução de } \\
\text { Problemas em contextos de } \\
\text { aprendizagem matemática }\end{array}$} & Silva/Medeiros (2012) & EBRAPEM \\
\hline & & & & \\
\hline
\end{tabular}

Fonte: Dados de pesquisa

O quinto foco temático é o único que não possui pesquisas envolvendo diretamente processos de aprendizagem com estudantes. Optamos por designar este foco de "Estudos com a RP no campo teórico-bibliográfico", pois envolve trabalhos com discussões teóricas como, por exemplo, a utilização da RP como disciplina curricular, a inserção da RP em livros didáticos, avaliações em larga escala, olimpíadas, pesquisa de mapeamento, entre outros. 
Os 25 trabalhos mapeados no quinto foco temático estão distribuidos na Tabela 8, sendo a maior concentração oriunda do Ebrapem. O subfoco temático que concentou o maior número de pesquisas é o que se refere a discussões envolvendo a RP em questões curriculares, teorias e livros didáticos. O trabalho de Andreatta e Allevato (2018), apresentado no Sipem, propôs uma discussão acerca da RP nos documentos de orientaçao curricular oficiais da Educação Básica Brasileira a partir dos PCN até a BNCC.

Tabela 8 - Distribuição dos trabalhos no quinto foco temático

\begin{tabular}{|c|c|c|c|c|}
\hline $\begin{array}{c}\text { Foco } \\
\text { Temático } \\
\end{array}$ & $\begin{array}{c}\mathrm{N}^{0} \mathrm{de} \\
\text { trabalhos }\end{array}$ & Subfoco & Autores & $\begin{array}{c}\text { Eventos/ } \\
\text { Periódicos } \\
\end{array}$ \\
\hline \multirow{27}{*}{$\begin{array}{c}\text { Estudos com } \\
\text { a RP no } \\
\text { campo } \\
\text { Teórico- } \\
\text { Bibliográfico }\end{array}$} & \multirow{8}{*}{08} & \multirow{8}{*}{$\begin{array}{l}\text { A RP como estratégia } \\
\text { para o ensino de teorias, } \\
\text { questões curriculares e } \\
\text { livros didáticos }\end{array}$} & Pommer/Pommer (2012) & REnCiMa \\
\hline & & & Assis (2013) & EBRAPEM \\
\hline & & & Gosztonyi (2016) & ICME \\
\hline & & & Teixeira/Allevato (2016) & REnCiMa \\
\hline & & & Bertini/Rocha (2018) & SIPEM \\
\hline & & & Martins et al. (2018) & SIPEM \\
\hline & & & Andreatta/Allevato (2018) & SIPEM \\
\hline & & & Carrión/Pluvinage (2019) & CIAEM \\
\hline & \multirow{4}{*}{04} & \multirow{4}{*}{$\begin{array}{l}\text { A RP no contexto } \\
\text { histórico da escola } \\
\text { primária em tempos do } \\
\text { escolanovismo }\end{array}$} & Virgens (2012) & EBRAPEM \\
\hline & & & Virgens (2013) & EBRAPEM \\
\hline & & & Almeida/Silva (2014) & Acta Scientiae \\
\hline & & & Souza $(2015)$ & EBRAPEM \\
\hline & \multirow{4}{*}{04} & \multirow{4}{*}{$\begin{array}{l}\text { Tendências e conexões } \\
\text { em RP com foco na } \\
\text { aprendizagem }\end{array}$} & Teixeira/Santos (2016) & Em Teia \\
\hline & & & Onuchic/Allevato (2018) & SIPEM \\
\hline & & & Kuhn (2019) & CIAEM \\
\hline & & & Allevato/Onuchic (2019) & REnCiMa \\
\hline & \multirow{4}{*}{04} & \multirow{4}{*}{$\begin{array}{l}\text { Mapeamento de pesquisas } \\
\text { apresentadas em eventos } \\
\text { científicos e e em } \\
\text { dissertações e teses }\end{array}$} & Stefani et al. (2018) & $\begin{array}{l}\text { Perspectivas da } \\
\text { Ed. Matemática }\end{array}$ \\
\hline & & & Andreatta/Allevato (2019) & CIAEM \\
\hline & & & Almeida/Huanca (2019) & CIAEM \\
\hline & & & Andreatta (2019) & EBRAPEM \\
\hline & \multirow{3}{*}{03} & \multirow{3}{*}{$\begin{array}{l}\text { A RP no contexto das } \\
\text { avaliações em larga } \\
\text { escala e Olimpíadas }\end{array}$} & Furlanetto/Dullius (2011) & EBRAPEM \\
\hline & & & Martino/Signorini (2016) & ICME \\
\hline & & & Grimaldos (2018) & EBRAPEM \\
\hline & \multirow[b]{2}{*}{01} & \multirow{2}{*}{$\begin{array}{l}\text { A metodologia de Ensino- } \\
\text { Aprendizagem-Avaliação de } \\
\text { Matemática através da RP }\end{array}$} & Huanca/Onuchic (2011) & EBRAPEM \\
\hline & & & & \\
\hline & \multirow[t]{2}{*}{01} & \multirow{2}{*}{$\begin{array}{l}\text { A RP e a Educação } \\
\text { Matemática como campo } \\
\text { de pesquisas teóricas }\end{array}$} & Morais (2016) & $\begin{array}{l}\text { Perspectivas da } \\
\text { Ed. Matemática }\end{array}$ \\
\hline & & & & \\
\hline
\end{tabular}

Fonte: Dados de pesquisa

O sexto foco temático concentrou o maior número de pesquisas, representando $31 \%$ (trinta e um por cento) de todos os trabalhos mapeados. Organizados na Tabela 9, representam o foco temático "Estudos com a RP sobre o professor de matemática: formação inicial e continuada". Diferente dos demais, o subfoco que concentrou o maior número de trabalhos está relacionado a leitura, interpretação e concepção de problemas matemáticos, com 28 artigos. Foram considerados 79 trabalhos neste foco temático. 
Tabela 9 - Distribuição dos trabalhos no sexto foco temático

\begin{tabular}{|c|c|c|c|c|}
\hline Foco Temático & $\begin{array}{c}\mathrm{N}^{0} \text { de } \\
\text { trabalhos }\end{array}$ & Subfoco & Autores & $\begin{array}{c}\text { Eventos/ } \\
\text { Periódicos }\end{array}$ \\
\hline \multirow{50}{*}{$\begin{array}{l}\text { Estudos com a } \\
\text { RP sobre o } \\
\text { professor de } \\
\text { matemática: } \\
\text { formação } \\
\text { inicial e } \\
\text { continuada }\end{array}$} & \multirow{28}{*}{28} & \multirow{28}{*}{$\begin{array}{l}\text { Leitura, interpretação e } \\
\text { concepção de problemas } \\
\text { matemáticos }\end{array}$} & Klein/Pereira (2011) & CIAEM \\
\hline & & & Lima/Manrique (2011) & CIAEM \\
\hline & & & Proença/Pirola (2011) & CIAEM \\
\hline & & & Azeredo et al. (2011) & CIAEM \\
\hline & & & Konig et al. (2012) & EBRAPEM \\
\hline & & & Malaspina et al. (2012) & ICME \\
\hline & & & Ferreira (2013) & EBRAPEM \\
\hline & & & Silva (2013c) & EBRAPEM \\
\hline & & & Santana (2014) & EBRAPEM \\
\hline & & & Stival (2015) & EBRAPEM \\
\hline & & & Santana (2015) & EBRAPEM \\
\hline & & & Pudelco (2015) & EBRAPEM \\
\hline & & & Oliveira/Passos (2015) & CIAEM \\
\hline & & & Vale/Barbosa (2015) & CIAEM \\
\hline & & & Pedro et al. (2015) & CIAEM \\
\hline & & & Stival (2016) & EBRAPEM \\
\hline & & & Lombardi (2016) & EBRAPEM \\
\hline & & & Pudelco (2016) & EBRAPEM \\
\hline & & & Tortora (2016) & EBRAPEM \\
\hline & & & Guerinet et al. (2016) & ICME \\
\hline & & & Urrea/Breda (2017) & Acta Scientiae \\
\hline & & & Cardozo (2018) & Amazônia \\
\hline & & & Rosa et al. (2018) & Amazônia \\
\hline & & & Mogue/Sanchez (2019) & CIAEM \\
\hline & & & Huanca/Assis (2019) & CIAEM \\
\hline & & & Sanchez et al. (2019) & CIAEM \\
\hline & & & Mitsuuchi (2019) & EBRAPEM \\
\hline & & & Mendes (2019) & EBRAPEM \\
\hline & \multirow{17}{*}{17} & \multirow{17}{*}{$\begin{array}{l}\text { A RP como estratégia de } \\
\text { ensino para o } \\
\text { desenvolvimento } \\
\text { conteúdos/conceitos } \\
\text { matemáticos }\end{array}$} & Castiblanco/Vargas (2011) & CIAEM \\
\hline & & & Azevedo/Onuchic (2011) & EBRAPEM \\
\hline & & & Cavalcante/Soares (2012) & SIPEM \\
\hline & & & Miller/Banes (2012) & ICME \\
\hline & & & Willian et al. (2012) & ICME \\
\hline & & & Silveira (2014) & EBRAPEM \\
\hline & & & Maia (2014) & EBRAPEM \\
\hline & & & Lima (2014b) & EBRAPEM \\
\hline & & & Matos et al. (2015) & CIAEM \\
\hline & & & Dias/Alves (2015) & CIAEM \\
\hline & & & Maia (2015) & EBRAPEM \\
\hline & & & Lago $(2016)$ & EBRAPEM \\
\hline & & & Etcheverria et al. (2016) & $\begin{array}{l}\text { Perspectivas da } \\
\text { Ed. Matemática }\end{array}$ \\
\hline & & & Maia (2018) & EBRAPEM \\
\hline & & & Proença (2018) & REnCiMa \\
\hline & & & Barreira (2019) & EBRAPEM \\
\hline & & & Gabriel (2019) & EBRAPEM \\
\hline & \multirow{5}{*}{07} & \multirow{5}{*}{$\begin{array}{l}\text { Estratégias/habilidades na } \\
\text { RP com diferentes } \\
\text { recursos e ambientes de } \\
\text { aprendizagem }\end{array}$} & Cavalcante/Rego (2011) & CIAEM \\
\hline & & & Fernandes Junior (2011) & EBRAPEM \\
\hline & & & Oliveira/Passos (2013) & Acta Scientiae \\
\hline & & & Eidelwein (2014) & EBRAPEM \\
\hline & & & Velandia/Leal (2015) & CIAEM \\
\hline
\end{tabular}




\begin{tabular}{|c|c|c|c|c|}
\hline \\
\hline & & & Sucupira (2015) & EBRAPEM \\
\hline & & & Liljedahl (2016) & ICME \\
\hline Foco Temático & $\begin{array}{c}\mathrm{N}^{0} \text { de } \\
\text { trabalhos }\end{array}$ & Subfoco & Autores & $\begin{array}{c}\text { Eventos/ } \\
\text { Periódicos }\end{array}$ \\
\hline \multirow{28}{*}{$\begin{array}{l}\text { Estudos com a } \\
\text { RP sobre o } \\
\text { professor de } \\
\text { matemática: } \\
\text { formação } \\
\text { inicial e } \\
\text { continuada }\end{array}$} & \multirow{5}{*}{05} & \multirow{5}{*}{$\begin{array}{l}\text { Estratégias/habilidades na } \\
\text { RP com diferentes } \\
\text { recursos e ambientes de } \\
\text { aprendizagem }\end{array}$} & Matejec (2017) & EBRAPEM \\
\hline & & & Kuster (2018) & EBRAPEM \\
\hline & & & Dantas/Baldiani (2018) & SIPEM \\
\hline & & & Silvas (2019) & EBRAPEM \\
\hline & & & Firão (2019) & EBRAPEM \\
\hline & \multirow{5}{*}{05} & \multirow{5}{*}{$\begin{array}{l}\text { A metodologia de Ensino- } \\
\text { Aprendizagem-Avaliação } \\
\text { de Matemática através da } \\
\text { RP }\end{array}$} & Justulin/Onuchic (2011) & EBRAPEM \\
\hline & & & Justulin (2014) & EBRAPEM \\
\hline & & & Nunes (2014) & REnCiMa \\
\hline & & & Costa/Allevato (2015) & CIAEM \\
\hline & & & Onuchic/Allevato (2015) & SIPEM \\
\hline & \multirow{5}{*}{05} & \multirow{5}{*}{$\begin{array}{l}\text { A metodologia de Ensino- } \\
\text { Aprendizagem-Avaliação } \\
\text { de Matemática através da } \\
\text { RP }\end{array}$} & Nunes/Santana (2017) & Acta Scientiae \\
\hline & & & Bicalho (2018) & EBRAPEM \\
\hline & & & Correa (2019) & EBRAPEM \\
\hline & & & Azevedo (2019) & EBRAPEM \\
\hline & & & Azevedo et al. (2019) & REnCiMa \\
\hline & \multirow{6}{*}{06} & \multirow{6}{*}{$\begin{array}{l}\text { A Formulação e Resolução de } \\
\text { Problemas em contextos de } \\
\text { aprendizagem matemática }\end{array}$} & Cunha (2013) & EBRAPEM \\
\hline & & & Silva (2013b) & EBRAPEM \\
\hline & & & Silva (2014a) & EBRAPEM \\
\hline & & & Silva (2014c) & EBRAPEM \\
\hline & & & Arenas/Rico (2015) & CIAEM \\
\hline & & & Yanez (2018) & REnCiMa \\
\hline & \multirow{3}{*}{03} & \multirow{3}{*}{$\begin{array}{l}\text { A Formulação e Resolução de } \\
\text { Problemas em contextos de } \\
\text { aprendizagem matemática }\end{array}$} & Abrão (2019) & EBRAPEM \\
\hline & & & Figueiredo/Groenwald (2019) & Acta Scientiae \\
\hline & & & Figueiredo/Groenwald (2019) & CIAEM \\
\hline & \multirow{4}{*}{03} & \multirow{4}{*}{$\begin{array}{l}\text { A RP como estratégia para o } \\
\text { ensino de teorias, questões } \\
\text { curriculares e livros } \\
\text { didáticos }\end{array}$} & Kliemann (2013) & EBRAPEM \\
\hline & & & Kliemann (2014) & EBRAPEM \\
\hline & & & Rocha (2018) & EBRAPEM \\
\hline & & & & \\
\hline
\end{tabular}

Fonte: Dados de pesquisa

Neste foco temático, vale destacar a continuidade de pesquisas de mesma autoria ${ }^{3}$ relacionadas à formação de professores. Ressaltamos as pesquisas de Azevedo (2019) e Azevedo et al. (2019), apresentadas no Ebrapem e na REnCiMa respectivamente, envolvendo trabalho de doutorado vinculado à Universidade do Minho, em Portugal, com pesquisa realizada no Brasil envolvendo a metodologia de Ensino-Aprendizagem-Avaliação de Matemática para ensinar conteúdos de Cálculo Diferencial e Integral através da Resolução de Problemas com estudantes de licenciatura em Matemática e Química da Universidade do Estado de Santa Catarina.

No cenário internacional foram identificados 5 trabalhos apresentados no ICME que abordaram a RP no contexto da formação de professores. Esses trabalhos são oriundos de

\footnotetext{
${ }^{3}$ Há outros trabalhos que possuem autoria homônima, porém não são da mesma pessoa, como é o caso de "Silva" e "Santana".
} 
vários países, como Estados Unidos, Peru, Espanha, Singapura, Irlanda e Canadá. De um modo geral, as pesquisas investigam o domínio e a concepção do professor na resolução de problemas matemáticos em seus contextos de atuação profissional, assim como a inserção da RP no currículo de matemática.

O sétimo e último foco temático foi o que ficou com o menor número de trabalhos, sendo dois apresentados na Ciaem e dois no Ebrapem. Este foco temático está organizado na Tabela 10, apresentada a seguir, e envolve estudos com a RP no campo da Educação Não Formal, principalmente no contexto da Educação Especial em instituições especializadas.

Tabela 10 - Distribuição dos trabalhos no sétimo foco temático

\begin{tabular}{|c|c|c|c|c|}
\hline $\begin{array}{c}\text { Foco } \\
\text { Temático }\end{array}$ & $\begin{array}{c}\mathrm{N}^{0} \mathrm{de} \\
\text { trabalhos }\end{array}$ & Subfoco & Autores & Eventos \\
\hline \multirow{6}{*}{$\begin{array}{l}\text { Estudos com } \\
\text { a RP no } \\
\text { campo da } \\
\text { Educação } \\
\text { Não Formal }\end{array}$} & \multirow{2}{*}{02} & \multirow{2}{*}{$\begin{array}{l}\text { A RP no contexto da } \\
\text { Educação Especial }\end{array}$} & Santos (2011) & EBRAPEM \\
\hline & & & Bezerra (2011) & EBRAPEM \\
\hline & \multirow[b]{2}{*}{01} & \multirow{2}{*}{$\begin{array}{l}\text { Estratégias/habilidades na RP } \\
\text { com diferentes recursos e } \\
\text { ambientes de aprendizagem }\end{array}$} & Costa et al. (2015) & CIAEM \\
\hline & & & & \\
\hline & & \multirow{2}{*}{$\begin{array}{lr}\text { A RP como estratégia } & \text { de } \\
\text { ensino para } & \text { o } \\
\text { desenvolvimento } & \text { de } \\
\text { conteúdos/conceitos } & \\
\text { matemáticos } & \end{array}$} & Meneghetti et al. (2011) & CIAEM \\
\hline & 01 & & & \\
\hline
\end{tabular}

Fonte: Dados de pesquisa

O trabahos que envolvem o subfoco da RP no contexto da Educação Especial exploram a RP em ambientes virtuais de aprendizagem, com o objetivo de melhorar o raciocínio e a aprendizagem dos estudantes da Educação Especial em relação aos conteúdos matemáticos.

\section{Considerações Finais}

A palavra "cenário" no título deste artigo foi utilizada com o objetivo de trazer à cena os contextos das pesquisas relacionadas a Elaboração, Formulação, Proposição e Resolução de Problemas apresentados nos eventos Ebrapem, Sipem Ciaem, Icme, ou publicadas nos periódicos Acta Scientiae, Amazônia, Em Teia, Perspectivas da Educação Matemática e REnCiMa, no período de 2011 a 2019. Buscando estes contextos, foi possível identicar focos e subfocos temáticos das pesquisas analisadas, assim como carências como a de investigações envolvendo RP na Educação Infantil.

$\mathrm{Na}$ Educação Básica, o número de pesquisas é bem significativo, além de presenciarmos pesquisas envolvendo a formação inicial e continuada de professores. Nos 
Ensino Fundamental e Médio, encontramos praticamente a mesma quantidade de trabalhos, sendo a maioria dos artigos relacionada ao contexto da RP com diferentes recursos e ambientes de aprendizagem, que vão desde a utilização de jogos e softwares educativos até materiais concretos, como sólidos geométricos.

No Ensino Superior, a maioria de trabalhos esteve direcionada à formação inicial e continuada de professores de matemática como de pedagogia, sendo a maior parte voltada para a formação inicial de professores de Matemática. No contexto das pesquisas teóricas, ou seja, não envolvendo pesquisas aplicadas, o número de artigos foi pequeno, sendo a maior parte deles direcionada à inserção da RP em livros didáticos e/ou relacionada a questões curriculares.

Em relação aos referenciais teóricos utilizados nos trabalhos mapeados, destacamos a forte presença das ideias de Polya (1978) como referencial principal, assim como de outros autores como Van de Walle (2009) e Schoenfeld (2007) como referenciais em segundo plano nas pesquisas. Destacamos alguns trabalhos como o de Cavalcante e Soares (2012) e Kuster (2018) dentre outros, que propuseram discussões apoiadas nesses referenciais teóricos supracitados.

Como referências de pesquisas desenvolvidas no Brasil e em um contexto de orientação metodológica de utilização da RP, encontramos muitos trabalhos que destacam as orientações de Onuchic e Allevato (2011) e Allevato e Onuchic (2014). A maior parte dos trabalhos citou ou utilizou a metodologia de Ensino-Aprendizagem-Avaliação de Matemática através da Resolução de Problemas proposta pelas autoras, em que são sugeridas etapas/passos que podem ser adotadas pelo professor na Resolução de Problemas em favor da aprendizagem de conteúdos matemáticos.

No contexto internacional dos trabalhos apresentados nas edições do ICME consideradas, também percebemos forte influência dos referenciais teóricos de Polya (1978) e do National Concil of Teachers of Mathematics - NCTM (1980, 1989, 2000), principalmente na edição de 2012, realizada na Coreia. Na edição de 2016, que ocorreu na Alemanha, destacam-se as referências a Schoenfeld (1992).

No geral, percebemos que a RP é um foco importante da pesquisa em Educação Matemática, tanto nos Estados Unidos quanto em outros países, assim como no Brasil. As contribuicões teóricas de Schoenfeld (2007) destacam a relevância dessa evolução das pesquisas envolvendo a RP, principalmente nos Estados Unidos, berço da propagação da Resolução de Problemas, a partir dos trabalhos de Polya e, posteriormente, do NCTM. 
Sendo assim, esperamos que este trabalho possa trazer indicações e contribuições ao desenvolvimento de futuras investigações envolvendo Elaboração, Formulação, Proposição e Resolução de Problemas, tendo em vista as diversas possibilidades de caminhos de pesquisas encontradas neste mapeamento, assim como possibilidades teóricas e metodológicas.

\section{Referências}

ALLEVATO, N. S. G.; ONUCHIC, L. R. Ensino-Aprendizagem-Avaliação de Matemática: por que Através da Resolução de Problemas. In: ONUCHIC, L. R.; ALLEVATO, N. S. G.; NOGUTI, F. C. H.; JUSTULIN, A. M. (Orgs.). Resolução de Problemas: Teoria e Prática. Jundiaí, Paco Editorial: 2014.

ALTOÉ, R. O.; FREITAS, R. C. O. Formulação de Problemas no Campo Conceitual Multiplicativo: uma proposta para o ensino de multiplicação e divisão no eixo de produto de medidas. Em Teia, Recife, v.10, n.3, p. 1-23, 2019.

ANDREATTA, C.; ALLEVATO, N. S. G. A Resolução de Problemas nos documentos de orientação curricular oficiais da Educação Básica Brasileira. In: SEMINÁRIO

INTERNACIONAL DE PESQUISA EM EDUCAÇÃO MATEMÁTICA, 07., 2018. Foz do Iguaçu, PR. Anais eletrônicos... Foz do Iguaçu: Sociedade Brasileira de Educação Matemática, SBEM, 2018, p.1-12. Disponível em: http://www.sbemparana.com.br/eventos/index.php/SIPEM/VII_SIPEM/paper/view/466/498. Acesso em: 08 dez. 2018.

AZEVEDO, E. B. Vivenciando a metodologia de Ensino-Aprendizagem-Avaliação através da Resolução de Problemas nas aulas de Cálculo Diferencial e Integral. In: ENCONTRO BRASILEIRO DE ESTUDANTES DE PÓS-GRADUAÇÃO EM EDUCAÇÃO MATEMÁTICA, 23., 2019, São Paulo, SP. Anais eletrônicos... São Paulo: Universidade Cruzeiro do Sul, Campus Anália Franco, 2019, p. 1-12. Disponível em: http://eventos.sbem.com.br/index.php/EBRAPEM/EBRAPEM2019/paper/view/252/994. Acesso em: 09 dez. 2019.

AZEVEDO, E. B.; FIGUEIREDO, E. B.; PALHARES, P. M. B. Análise da variação de Funções ensinada através da Resolução de Problemas. REnCiMa, São Paulo, v. 10, n. 5, p. 32-52, 2019.

CAVALCANTE, J. L.; SOARES, L. H. Resolução de Problemas e formação docente: saberes e vivências no curso de pedagogia. In: SEMINÁRIO INTERNACIONAL DE PESQUISA EM EDUCAÇÃO MATEMÁTICA, 05., 2012. Petrópolis, RJ. Anais eletrônicos... Petrópolis: Sociedade Brasileira de Educação Matemática, SBEM, 2012, p.1-19. Disponível em: http://www.sbembrasil.org.br/files/v_sipem/PDFs/GT07/CC00977083489_A.pdf. Acesso em: 08 dez. 2018.

DULLIUS, M. M.; ALTHAUS, N. M.; AMADO, N. M. P. Jogo computacional e resolução de problemas: uma experiência com alunos do $6^{\circ}$ ano. In: SEMINÁRIO INTERNACIONAL DE PESQUISA EM EDUCAÇÃO MATEMÁTICA, 06., 2015. Pirenópolis, GO. Anais 
eletrônicos... Pirenópolis: Sociedade Brasileira de Educação Matemática, SBEM, 2015, p.112. Disponível em: http://www.sbembrasil.org.br/visipem/anais/story_html5.html. Acesso em: 08 dez. 2018.

FIORENTINI, D. Rumos da pesquisa brasileira em Educação Matemática: o caso da produção científica em cursos de pós-graduação. 1994. 414f. Tese (Doutorado em Educação) - Programa de Pós-Graduação em Educação, Universidade Estadual de Campinas, Campinas, 1994.

FIORENTINI, D. Mapeamento e balanços dos trabalhos do GT-19 (Educação Matemática) no período de 1998 a 2001. In: REUNIÃO ANUAL DA ASSOCIAÇÃO NACIONAL DE PÓSGRADUAÇÃO E PESQUISA EM EDUCAÇÃO - ANPED, 25., 29 de setembro a 02 de outubro de 2002, Caxambu. Disponível em:

http://www.ufrrj.br/emanped/paginas/conteudo_producoes/docs_25/mapeamento.pdf. Acesso em: 03 nov. 2017.

FIORENTINI, D.; LORENZATO, S. Investigação em Educação Matemática: percursos teóricos e metodológicos. 3. ed. rev. Campinas, SP: Autores Associados, 2012.

FURLANETTO, V.; DULLIUS, M. M. Alunos da Educação Básica Explorando Estratégias Diferenciadas na Resolução de Problemas Matemáticos. In: ENCONTRO BRASILEIRO DE ESTUDANTES DE PÓS-GRADUAÇÃO EM EDUCAÇÃO MATEMÁTICA, 16., 2012, Canoas, RS. Anais eletrônicos... Canoas: Universidade Luterana do Brasil, 2012, p. 1-12. Disponível em:

http://matematica.ulbra.br/ocs/index.php/ebrapem2012/xviebrapem/schedConf/presentations. Acesso em: 08 dez. 2018.

KUSTER, J. S. Formação de professores em ações colaborativas para aula de resolução de problemas: contribuições e desafios. In: ENCONTRO BRASILEIRO DE ESTUDANTES DE PÓS-GRADUAÇÃO EM EDUCAÇÃO MATEMÁTICA, 22., 2018, Belo Horizonte, MG. Anais eletrônicos... Belo Horizonte: Universidade Federal de Minas Gerais, 2018, p. 1-12. Disponível em:

http://sbem.iuri0094.hospedagemdesites.ws/eventos/index.php/EBRAPEM/index/pages/view/ anais2018. Acesso em: 08 dez. 2018.

MORAIS, R. dos S. O processo constitutivo da resolução de problemas como uma temática da pesquisa em educação matemática: um inventário a partir de documentos dos ICMEs. 2015. 471f. Tese (Doutorado em Educação Matemática) - Universidade Estadual Paulista "Júlio de Mesquita Filho", Rio Claro, 2015.

MULLER, A. P. K.; DULLIUS, M. M. Resolução de Problemas: diferentes abordagens no ensino de matemática. In: SEMINÁRIO INTERNACIONAL DE PESQUISA EM EDUCAÇÃO MATEMÁTICA, 07., 2018. Foz do Iguaçu, PR. Anais eletrônicos... Foz do Iguaçu: Sociedade Brasileira de Educação Matemática, SBEM, 2018, p.1-11. Disponível em: http://www.sbemparana.com.br/eventos/index.php/SIPEM/VII_SIPEM/paper/view/452/314. Acesso em: 08 dez. 2018. 
NATIONAL COUNCIL OF TEACHERS OF MATHEMATICS. An Agenda for Action. Reston: NCTM, 1980.

\section{NATIONAL COUNCIL OF TEACHERS OF MATHEMATICS. Curriculum and Evaluation Standards for School Mathematics. Reston: NCTM, 1989.}

\section{NATIONAL COUNCIL OF TEACHERS OF MATHEMATICS. Principles and Standards for School Mathematics. Reston: NCTM, 2000.}

ONUCHIC, L. R.; ALLEVATO, N. S. G. Pesquisa em Resolução de Problemas: caminhos, avanços e novas perspectivas. Boletim de Educação Matemática, Rio Claro, v. 25, n. 41, p. 73-98, dez, 2011.

PAGANI, E. M. L. O ensino-aprendizagem-avaliação de derivadas no curso técnico integrado ao médio através da resolução de problemas. In: ENCONTRO BRASILEIRO DE ESTUDANTES DE PÓS-GRADUAÇÃO EM EDUCAÇÃO MATEMÁTICA, 19., 2015, Juiz de Fora, MG. Anais eletrônicos... Juiz de Fora: Universidade Federal de Juiz de Fora, 2015, p. 1-12. Disponível em:

http://www.ufjf.br/ebrapem2015/files/2015/10/GD14_Erica_Pagani.pdf. Acesso em: 08 dez. 2018.

PAGANI, E. M. L. A (re) construção de saberes matemáticos proporcionada pela metodologia de Ensino-Aprendizagem-Avaliação de derivadas através da Resolução de Problemas. In: CONFERÊNCIA INTERAMERICANA DE EDUCAÇÃO MATEMÁTICA, 15., 2019, Medellin, Colômbia. Anais eletrônicos... Colômbia: Universidad De Medellin, 2019, p. 1-8. Disponível em: http://conferencia.ciaemredumate.org/index.php/xvciaem/xv/paper/viewFile/387/431. Acesso em: 07 jul. 2019.

PAGANI, E. M. L.; ALLEVATO, N. S. G. O trabalho com Derivadas no Ensino Médio através da Resolução de Problemas: aspectos da avaliação. REnCiMa, São Paulo, v. 7, n. 1, p. 86-101, 2016.

POLYA, G. A arte de resolver problemas. Trad. e adapt. de Heitor Lisboa de Araújo. Rio de Janeiro: Interciência, 1978 [1945].

ROMANOWSKI, J. P.; ENS, R. T. As pesquisas denominadas do tipo "estado da arte" em educação. Diálogo Educ., Curitiba, v. 6, n. 19, p. 37-50, set./dez. 2006. Disponível em: http://alfabetizarvirtualtextos.files.wordpress.com/2011/08/as-pesquisasdenominadas-do-tipoestado-da-arte-em-educac3a7c3a3o.pdf. Acesso em: 03 nov. 2017.

SCARLASSARI, N. T.; LOPES, C. E. Mapeamento dos trabalhos publicados no GT 12 do SIPEM. In: SEMINÁRIO INTERNACIONAL DE PESQUISA EM EDUCAÇÃO MATEMÁTICA, 07., 2018. Foz do Iguaçu, PR. Anais eletrônicos...Foz do Iguaçu: Sociedade Brasileira de Educação Matemática, SBEM, 2018, p.1-17. Disponível em: http://www.sbemparana.com.br/eventos/index.php/SIPEM/VII_SIPEM/paper/view/532/279. Acesso em: 08 dez. 2018. 
SCHOENFELD, A. H. Learning to think mathematically: Problem solving, metacognition, and sense making in mathematics. In: GROUWS, D. (Ed.). Handbook of research on mathematics teaching and learning. New York: McMillan, 1992. p. 334-370.

SCHOENFELD, A. H. Problem solving in the United States, 1970 -2008: research and theory, practice and politics. ZDN Mathematics Education, Karlsruhe, n. 39, p. 537-551. 2007.

SOCIEDADE BRASILEIRA DE EDUCAÇÃO MATEMÁTICA. Boletim - SBEM, v. 11. Universidade de Brasília (UnB), Campus Darcy Ribeiro. Brasília, p. 1-10. 2012. Disponível em: http://www.sbembrasil.org.br/files/Boletim11.pdf. Acesso em: 10 jul. 2019.

TORTORA, E. O ensino de Matemática na Educação Infantil e no primeiro ano do Ensino Fundamental. In: ENCONTRO BRASILEIRO DE ESTUDANTES DE PÓS-GRADUAÇÃO EM EDUCAÇÃO MATEMÁTICA, 20., 2016, Curitiba, PR. Anais eletrônicos... Curitiba: Universidade Federal do Paraná, 2016, p. 1-12. Disponível em:

http://www.ebrapem2016.ufpr.br/wpcontent/uploads/2016/04/gd1_evandro_tortora.pdff. Acesso em: 08 dez. 2018.

UNIVERSIDADE CRUZEIRO DO SUL. Revista de Ensino de Ciências e Matemática REnCiMa. Editora da Unicsul. São Paulo, 2020. Disponível em:

http://revistapos.cruzeirodosul.edu.br/index.php/rencima. Acesso em: 06 jan. 2020.

UNIVERSIDADE FEDERAL DE MATO GROSSO DO SUL. Perspectivas da Educação Matemática. Editora da UFMS. Campo Grande, 2020. Disponível em:

https://periodicos.ufms.br/index.php/pedmat/about. Acesso em: 06 jan. 2020.

UNIVERSIDADE FEDERAL DE PERNAMBUCO. Revista de Educação Matemática e Tecnológica Iberoamericana. Editora da UFPE. Recife, 2020. Disponível em: https://periodicos.ufpe.br/revistas/emteia/index. Acesso em: 06 jan. 2020.

UNIVERSIDADE FEDERAL DO PARÁ. Revista de Educação em Ciências e Matemática - Amazônia. Editora da UFPA. Belém, 2020. Disponível em:

https://periodicos.ufpa.br/index.php/revistaamazonia/index. Acesso em: 06 jan. 2020.

UNIVERSIDADE LUTERANA DO BRASIL. Revista de Ensino de Ciências e Matemática - Acta Scientiae. Editora da Ulbra. Canoas, 2020. Disponível em: http://www.periodicos.ulbra.br/index.php/acta/. Acesso em: 06 jan. 2020.

VAN de WALLE, J. A. Matemática no Ensino Fundamental: formação de professores e aplicação em sala de aula. Tradução de P. H. Colonese. 6. ed. Porto Alegre: Artmed, 2009. 